\title{
Correction to: Contribution of the MRPS22 variant and a Down mosaic to the phenotype
}

Josef Finsterer $^{1} \cdot$ Sinda Zarrouk-Mahjoub ${ }^{2}$

Published online: 18 October 2017

(C) Springer Science+Business Media, LLC 2017

Correction to: Metab Brain Dis (2017)

https://doi.org/10.1007/s11011-017-0115-0

In the original publication of the article, the title was incorrectly written as "The cerebellum is a common site of affection in Leigh syndrome." The correct title is "Contribution of the MRPS22 variant and a Down mosaic to the phenotype."

The online version of the original article can be found at https://oi.org/ 10.1007/s11011-017-0115-0

Josef Finsterer

fifigs1@yahoo.de

Krankenanstalt Rudolfstiftung, Postfach 20, 1180 Vienna, Austria

2 University of Tunis El Manar and Genomics Platform, Pasteur Institute of Tunis, Tunis, Tunisia 